\title{
COMPARISON OF HEMODYNAMIC AND NEUROMUSCULAR PROPERTIES OF ROCURONIUM VERSUS VECURONIUM IN ANESTHESIA
}

\section{Anaesthesiology}

Dr. Rajeev Krishan

MBBS, M.D. (Anaes.), Senior Resident, Department of Anaesthesia, Sri Krishna Medical College \& Hospital, Muzaffarpur, Bihar.

\begin{tabular}{|c|c|}
\hline $\begin{array}{l}\text { Dr. Praveen } \\
\text { Kumar Singh* }\end{array}$ & $\begin{array}{l}\text { MBBS, M.D. (Anaes.),Senior Resident, Department of Anaesthesia, Sri Krishna Medical } \\
\text { College \& Hospital, Muzaffarpur, Bihar. *Corresponding Author }\end{array}$ \\
\hline $\begin{array}{l}\text { Dr. Chandeshwar } \\
\text { Choudhary }\end{array}$ & $\begin{array}{l}\text { MBBS, M.D. (Anaes.), Associate Professor, Department of Anaesthesia, Sri Krishna } \\
\text { Medical College \& Hospital, Muzaffarpur, Bihar. }\end{array}$ \\
\hline Dran & $\begin{array}{l}\text { Young Scientist (DST), Institute of Post-Graduate Medical Education and Research, } \\
\text { A.J.C. Bose Road, Kolkata-700020, West Bengal, India. }\end{array}$ \\
\hline
\end{tabular}

\section{ABSTRACT}

Background: Adequate maintenance of airways in patients undergoing surgeries under general anesthesia was through proper intubation. This was achieved by the extensive usage of neuromuscular blocking drugs, which provided good intubation conditions and relaxation of the muscles. Neuromuscular blockers play a key role in general anesthesia. Rocuronium and vecuronium are used as nondepolarizing muscle relaxants.

Objective: To study the neuromuscular properties and cardiovascular effects of rocuronium bromide, the "near-ideal" muscle relaxant and to compare it with vecuronium bromide, an already established drug, during anesthesia.

Materials and Methods: This prospective, randomized double-blinded clinical study included 50 patients, 25 patients received $0.6 \mathrm{mg} / \mathrm{kg}$ of rocuronium bromide for the maintenance of anesthesia and the other 25 patients received $0.1 \mathrm{mg} / \mathrm{kg}$ of vecuronium bromide. The top-up doses administered were $0.15 \mathrm{mg} / \mathrm{kg}$ of rocuronium and $0.025 \mathrm{mg} / \mathrm{kg}$ of vecuronium.

Result: The onset time was significantly shorter in the rocuronium group (Mean \pm standard deviation [SD] was $108.8 \mathrm{~s} \pm 28.875 \mathrm{~s}$ ) compared with vecuronium group (Mean \pm SD $188.76 \mathrm{~s} \pm 43.78 \mathrm{~s}$ ). The duration of action of first dose was significantly longer in rocuronium group (31.5 min) compared with vecuronium group $(24.5 \mathrm{~min})$. The duration of action of top-up doses was similar in both the groups $(p>0.05)$. There was no significant difference in any of the haemodynamic variables between the two groups.

Conclusion: The duration of action of top-up doses was similar in both the groups $(p>0.05)$. There was no significant difference in any of the hemodynamic variables (heart rate, systolic blood pressure, diastolic blood pressure, and mean arterial pressure) between the two groups.

\section{KEYWORDS}

Rocuronium, vecuronium, neuromuscular blocking agents, hemodynamics

\section{INTRODUCTION}

Neuromuscular blocking agents are firmly entrenched as an integral part of everyday anesthesia practice. The use of muscle relaxants not only revolutionized the practice of anes-thesia but also started the modern era of surgery and made possible the explosive development of cardiothoracic, neuro logical, and organ transplant surgery. Muscle relaxation is helpful in performing endotracheal intubation and in providing surgical relaxation.

The onset time, duration of muscle relaxation, and the type of surgery are the critical factors in choosing the appropri-ate muscle relaxant to achieve rapid and successful tracheal intubation.

Rocuronium bromide, ORG-9246, a newer nondepolarizing muscle relaxant with quick onset and intermediate duration of action has onesixth of potency of vecuronium, which was introduced in the 1990s. It is similar in structure and properties to vecuronium but had an added advantage of rapid onset of action and unchanged excretion in urine, thereby, eliminating the side effects of the metabolites. Its introduction is consid-ered as an added advantage over vecuronium.

Sehgal et al. did a comparable evaluation of intubating conditions, onset of action, and duration of action of rocu-ronium bromide and vecuronium bromide. They found that rocuronium provides clinically acceptable intubating conditions much earlier than vecuronium.

This study was aimed to determine the efficacy of rocuronium, a newer nondepolarizing neuromuscular blocking agent, compared with vecuronium for rapid sequence intubation.

\section{MATERIALS AND METHODS}

This was a randomized, prospective clinical double-blinded study conducted over a period of 2 years from May 2018 to April 2020 in the department of anesthesia at Sri Krishna Medical College and Hospital, Muzaffarpur, Bihar. In this study, 100 patients aged between 18 and 55 years belonging to ASA class 1 or 2 (ASA-American Society of Anaesthesiologists) were randomly divided into two groups, each group consisting of 50 patients. Patients were randomized into one of the two groups, group V (vecuronium) and group R (rocuronium) of 50 each for induction and maintenance of anesthesia.

\section{INCLUSION CRITERIA}

1. Patients in age group of 18 to 55 years

2. ASA grade 1 or 2

3. Mallampati class 1 or 2

4. Patients who underwent selected general surgeries, ear, nose, and throat surgeries, gynecological surgeries, ortho-pedic surgeries, and so on

\section{EXCLUSION CRITERIA}

Patients with difficulty in airway (Mallampatti class 3 or 4), gastroesophageal reflux disease, hypertensive patients, allergic to the drugs used, history of cardiovascular or renal disorders, chain smokers, patients with neuromuscular disorders, and pregnant patients were excluded from this study.

Preanesthetic assessment was done the evening before the day of surgery. A detailed history was taken; examination and investigation were reviewed. Informed consent was obtained. Tablet diazepam (5 $\mathrm{mg}$ ) and tablet ranitidine $(150 \mathrm{mg})$ was given the night before the surgery and $1.5 \mathrm{~h}$ before the time of surgery on the morning of the day of the surgery. All the patients were fasting for at least $6 \mathrm{~h}$ before surgery.

Before the induction of anesthesia, patients in both groups were premedicated with midazolam $0.025 \mathrm{mg} / \mathrm{kg}$, injection glycopylorate 5 $\mathrm{mg} / \mathrm{kg}$, and fentanyl $1 \mathrm{mg} / \mathrm{kg}$. Patients were preoxygenated with oxygen $100 \%$ for a period of $3 \mathrm{~min}$ followed by the induction of the patients with injection thiopentone $4 \mathrm{mg} / \mathrm{kg}$ intravenously. At this point, the train of four stimuli was done and its basal readings noted. Four supramaximal stimuli were given before the injection of neuromuscular blockade and followed by every $30 \mathrm{~s}$ after the drug has been administered. Each stimulus in the train causes the muscles to contract and fade, and the response provides the basis of evaluation. Patients in group V received vecuronium $0.1 \mathrm{mg} / \mathrm{kg}$ and those in group $\mathrm{R}$ received rocuronium $0.6 \mathrm{mg} / \mathrm{kg}$. 
Hemodynamic parameters such as systolic blood pressure (BP), diastolic BP, and heart rate were recorded at base line during preoxygenation and at 1,3,5, and 10 min after induction. Trachea was intubated using a suitable size portex endotracheal tube. Anesthesia was then maintained with $40 \% \mathrm{O}_{2}$ and $60 \% \mathrm{~N}_{2} \mathrm{O}$. After 10 min of an effective tracheal intubation, for every $5 \mathrm{~min}$, train of four stimulations was recorded and the ratio between the first and fourth stimuli was calculated and accordingly muscle relaxants in a maintenance dose of injection vecuronium $0.025 \mathrm{mg} / \mathrm{kg}$ and injection rocuronium 0.15 $\mathrm{mg} / \mathrm{kg}$ was administered and maintained, anesthesia was continued with $\mathrm{O} 2, \mathrm{~N} 2 \mathrm{O}$, and halothane. During the con-duct of anesthesia, patients vital were monitored regularly. Pre extubation, train of four stimuli was done and only after appropriate ratio was obtained $(>0.7)$. The patients were administered reversal with injection neostigmine $0.05 \mathrm{mg} / \mathrm{kg}$ and injection glycopylorate $5 \mathrm{mg} / \mathrm{kg}$. After appropriate suctioning extubation was done and again a train of four stimuli was done after 3 min and readings were measured.

\section{RESULT}

The highest age in the study group was 55 years and the lowest age was 18 years. The majority of the patients were in between 31 and 40 years of age $(40 \%)$ in group $V$ whereas it was between 41 and 50 years $(40 \%)$ in group R. Only one patient in group V was below 20 years of age. The mean age was 34.64 years in group $V$ whereas it was 37.20 years in group $\mathrm{R}$. The difference in the mean age of the patients between the two groups was not statistically significant $(p=0.332)$.

The study comprised a total of 40 male patients and 60 female patients. Group V comprised $60 \%$ (30) male patients and $40 \%$ (20) female patients whereas group R comprised $20 \%$ (10) male patients and $80 \%$ (40) female patients. The result of sex distribution was not statistically significant $(p=0.258)$.

The duration of action between the two groups was that group R had a longer duration of action when compared with vecuronium and it also had a significant $p$ value of 0.01 . The top-up doses also indicated that rocuronium seems to have a prolonged action than Vecuronium (Table $1)$.

Table 1 : Duration of action of initial and top-up doses

\begin{tabular}{|l|c|c|c|c|}
\hline \multicolumn{1}{|c|}{ Doses } & \multicolumn{2}{c|}{ Group V } & \multicolumn{2}{c|}{ Group R } \\
\hline & Mean (Min) & SD & Mean (Min) & SD \\
\hline Initial dose & 24.5 & 7.54 & 31.5 & 8.9 \\
\hline First top-up & 24.73 & 5.5 & 28.48 & 4.8 \\
\hline Second top-up & 24.44 & 6.6 & 28.14 & 5.27 \\
\hline Third top-up & 23.50 & 7.36 & 28.25 & 6.8 \\
\hline Fourth top-up & 20.50 & 6.65 & 31.50 & 2.12 \\
\hline Fifth top-up & 25 & - & - & - \\
\hline
\end{tabular}

$\mathrm{V}$, vecuronium; R, rocuronium; $\mathrm{SD}$, standard deviation.

In comparison between the two drugs, there does not seem to be a drastic variation in the heart rate, systolic and diastolic BP, and the respiratory rate. There was only one patient who had a high systolic BP before the induction of anesthesia and which later got optimized after the induction of anesthesia without any antihypertensives (Table 2) (Figure 1).

Table 2 : Values of hemodynamic responses

\begin{tabular}{|c|c|c|c|c|c|c|}
\hline \multirow[t]{2}{*}{ Time } & \multicolumn{2}{|c|}{ Heart Rate } & \multicolumn{2}{|c|}{$\begin{array}{c}\text { Systolic Blood } \\
\text { Pressure }\end{array}$} & \multicolumn{2}{|c|}{$\begin{array}{c}\text { Diastolic Blood } \\
\text { Pressure }\end{array}$} \\
\hline & Group V & Group R & Group V & Group R & Group I & Group R \\
\hline 0 & 85.84 & 84.96 & 128.16 & 129.04 & 81.84 & 84.00 \\
\hline 2 & .52 & & 36 & 128.48 & .76 & 5.92 \\
\hline 4 & .76 & & 132.96 & 129.20 & 84.48 & 7.76 \\
\hline 6 & 2.84 & 60 & 130.88 & 126.40 & 82.88 & 86.40 \\
\hline 8 & 0.64 & 2.12 & 128.40 & 126.72 & 80.80 & 83.92 \\
\hline 10 & 78.60 & 1.44 & 128.08 & 125.20 & 81.44 & 81.68 \\
\hline 15 & 78.20 & 9.88 & 170.28 & 165.20 & 81.76 & 81.52 \\
\hline 20 & 77.84 & .48 & 125.76 & 126.16 & 82.72 & 81.92 \\
\hline 25 & 79.56 & .16 & 124.16 & 128.16 & 83.04 & 81.04 \\
\hline 30 & 78.88 & & 124 & 126.48 & 82.80 & 81.68 \\
\hline 45 & 77.88 & & 125.44 & 123.28 & 81.92 & 82.00 \\
\hline 60 & 7.36 & & 124.56 & 122.16 & 80.72 & 80.24 \\
\hline 75 & 79.04 & 79.68 & 125.28 & 123.92 & 80.64 & 81.04 \\
\hline 90 & 77.80 & 79.64 & 124.80 & 122.96 & 81.04 & 80.96 \\
\hline
\end{tabular}

\begin{tabular}{|l|l|l|l|l|l|l|}
\hline 105 & 79.36 & 81.24 & 124.72 & 123.36 & 80.96 & 80.32 \\
\hline 120 & 79.20 & 80.28 & 126.16 & 124.32 & 80.24 & 81.92 \\
\hline 360 & 78.80 & 76.80 & 124.88 & 126.88 & 80.80 & 82.64 \\
\hline
\end{tabular}

$\mathrm{V}$, vecuronium; $\mathrm{R}$, rocuronium

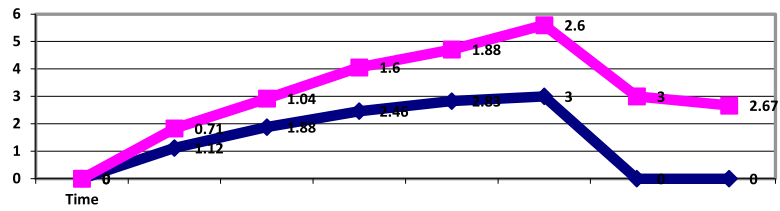

Figure 1: Time specific changes in Cooper score in two drug groups

\section{DISCUSSION}

The mean time for the onset of action was $108.8 \mathrm{~s}$ in rocuronium group and it was $188.76 \mathrm{~s}$ in vecuronium group, and it was statistically highly significant $(p<0.001)$. The duration of action of initial dose was 31.5 min in rocuronium group and it was $24.5 \mathrm{~min}$ in vecuronium group. The duration of action of initial dose was significantly longer in rocuronium group compared with vecuronium group $(p<0.01)$. The duration of action of top-up doses was 25-29 min in rocuronium group and it was 24-28 min in vecuronium group. The duration of action of each top-up dose was similar in both the groups with no significant difference in $p$ value

In this study, in group $\mathrm{V}$, the heart rate at preinduction level was 85.48 beats $/ \mathrm{min}$. At the onset of action of vecuronium, the heart rate was 85.52 beats $/ \mathrm{min}$. This is correlating with the studies by Booth et al. and Schramm et al. Robertson et al. compared atracurium and vecuronium and found that no significant changes in heart rate were seen after the injection of vecuronium. Wierda et al. studied pharmacodynamics of vecuronium in doses up to $0.4 \mathrm{mg} / \mathrm{kg}$ and found no adverse hemodynamic effects.

In this study, in group $\mathrm{R}$, the heart rate at preinduction level was 84.96 beats/min. At the onset of action of rocuronium, the heart rate was 83.60 beats $/ \mathrm{min}$. The finding of this study is in agreement with the study by Maddineni et al. This observation also correlates with the study by Hudson et al. with rocuronium in a dose of $0.6 \mathrm{mg} / \mathrm{kg}$ wherein they concluded that no changes in heart rate occurred with the given dose of rocuronium. Levy et al. studied the heart rate changes with rocuronium in doses ranging from $0.6 \mathrm{mg} / \mathrm{kg}$ to $1.2 \mathrm{mg} / \mathrm{kg}$ and found no significant changes in heart rate even in high doses.

In group $\mathrm{V}$, the systolic $\mathrm{BP}$ at preinduction level was $128.16 \mathrm{~mm}$ of $\mathrm{Hg}$. At the onset, BP was $130.52 \mathrm{~mm}$ of $\mathrm{Hg}$. The diastolic pressure at preinduction level was $81.84 \mathrm{~mm}$ of $\mathrm{Hg}$ and it was $81.60 \mathrm{~mm}$ of $\mathrm{Hg}$ just before the administration of vecuronium. At the onset of action of vecuronium, the diastolic pressure was $82.12 \mathrm{~mm}$ of $\mathrm{Hg}$. The finding of this study that vecuronium did not cause any significant change in BP is in accordance with the studies by Wierda et al. and Robertson et al.

In group R, the systolic BP at preinduction level was $129.04 \mathrm{~mm}$ of Hg. At the onset of action of rocuronium, the systolic BP was $128.48 \mathrm{~mm}$ of $\mathrm{Hg}$. Throughout the study period, the systolic BP remained between $122.16 \mathrm{~mm}$ of $\mathrm{Hg}$ and $128.16 \mathrm{~mm}$ of $\mathrm{Hg}$. The diastolic pressure at preinduction level was $84 \mathrm{~mm}$ of $\mathrm{Hg}$. At the onset of action of rocuronium, the diastolic BP was $85.92 \mathrm{~mm}$ of $\mathrm{Hg}$. Throughout the study period, the diastolic BP remained between $80.24 \mathrm{~mm}$ of $\mathrm{Hg}$ and $86.18 \mathrm{~mm}$ of $\mathrm{Hg}$. This correlates with the study by Levy et al. who determined the hemodynamics and histamine release of rocuronium when administered in increased doses.

\section{CONCLUSION}

Rocuronium has a significantly rapid onset of action and intermediate duration of action. It is easily reversible and produces no significant cardiovascular changes. It also has a good safety profile. Therefore, in spite of its high cost and limited availability, rocuronium appears to be a safe drug for rapid sequence intubation when there is no anticipated difficulty in intubation and also in surgeries of prolonged duration without any adverse cardiovascular effects. Cardiovascular effects of muscle relaxant may be produced by muscarinic receptor block, ganglion block, increased noradrenaline release, and blockade of its uptake, or histamine liberation. Neuromuscular blocking agents vary widely with regard to their cardiovascular effects. Among the established agents, tubocurarine, gallamine, and pancuronium exert significant cardiovascular effects; atracurium and mivacurium produce minor changes in cardiovascular variables whereas vecuro- 
nium and rocuronium are associated with a high degree of cardiostability.

\section{REFERENCES}

Booij LHDJ, Marshall RJ, Crul JF, Muir AW. Pharmacology of four steroidal muscle relaxants. 9th World Congress of Anaesthesiol-ogists, A0533; 1988; Washington DC.

2. Booth MG, Marsh B, Bryden FM, Robertson EN, Baird WL. A comparison of the pharmacodynamics of rocuronium and vecuronium during halothane anaesthesia. Anaesthesia 1992; 47(10):832-4.

3. Cooper RA, Mirakhur RK, Maddineni VR. Neuromuscular effects of rocuronium bromide (Org 9426) during fentanyl and halothane anaesthesia. Anaesthesia 1993;48(2):103-5.

4. Feldman Stanley. Neuromuscular transmission, In: Miller RD, editor. Atlas of Anesthesia. Churchill Livingstone, 1998; Chapter 8, p.8.1-8.89.

5. Fuchs-Buder T, Tassonyi E. Intubating conditions and time course of rocuroniuminduced neuromuscular block in children. Br J Anaesth 1996;77(3):335-8.

6. Hudson ME, Rothfield KP, Tullock WC, Firestone LL. Haemo-dynamic effects of rocuronium bromide in adult cardiac surgical patients. Can J Anaesth 1998;45(2):139-43.

7. Levy JH, Davis GK, Duggan J, Szlam F. Determination of the hemodynamics and histamine release of rocuronium (Org 9426) when administered in increased doses under N2O/O2-sufentanil anesthesia. Anesth Analg 1994;78(2):318-21.

8. Maddineni VR, McCoy EP, Mirakur RK, McBride RJ. Onset and duration of action and hemodynamic effects of rocuronium bromide under balanced and volatile anesthesia. Acta Anaesthesiol Belg 1994;45(2):41-7.

9. Misra MN, Agarwal M, Pandey RP, Gupta A. A comparative study of rocuronium, vecuronium and succinylcholine for rapid sequence induction of anaesthesia. Indian J Anaesth 2005; 49(6):469-73.

10. Padmaja D, Mantha S. Monitoring of neuromuscular junctions. Indian J Anaesth 2002;46(4):279-88.

11. Robertson EN, Booij LH, Fragen RJ, Crul JF. Clinical comparison of atracurium and vecuronium (Org NC 45). Br J Anaesth 1983; 55(2):125-9.

12. Schramm WM, Strasser K, Bartunek A, Gilly H, Spiss CK. Effects of rocuronium and vecuronium on intracranial pressure, mean arterial pressure and heart rate in neurosurgical patients. Br J Anaesth 1996;77(5):607-11

13. Sehgal A, Sharma RK, Kumar IH. Comparison of intubating conditions and time course of action of rocuronium bromide and vecuronium bromide. Indian J Anaesth 2001;45(4):255-8.

14. Somani M, Sharma P, Sachdev S, Mathur V, Chaturvedi S. A Compari Tive study between vecuronium and rocuronium for intubating condition and hemodynamic changes. IOSR J Dental Med Sci 2014;13(6):33-9.

15. Vickers MD, Morgan M, Spencer PSJ. Drugs in Anaesthesia Practice, 7th ed. Oxford: Butterworth Heinemann Ltd; 1991, pp 348-349.

16. Wierda JM, Maestrone E, Bencini AF, Boyer A, Rashkovsky OM, Lip H, et al. Haemodynamic effects of vecuronium. Br JAnaesth 1989;62(2):194-8. 